\title{
SISTEM PENGONTROLAN PEMBUDIDAYAAN TERNAK AYAM DENGAN MEDIA KANDANG VIA BLUETOOTH MENGGUNAKAN SMARTPHONE BERBASIS ARDUINO UNO
}

\author{
Lahuddin $^{1}$ \\ Saptono Ramadhan ${ }^{2}$ \\ Zulfa Fiatikara $^{3}$ \\ ${ }^{I}$ Dosen STMIK Raharja \\ ${ }^{2,3}$ Mahasiswa STMIK Raharja \\ Jl. Jendral Sudirman No. 40, Modernland, Tangerang \\ Email: lahuddin@ @aharja.info ${ }^{1}$, saptono.ramadhan@raharja.info ${ }^{2}$, zulfa.fiatikara@raharja.info $^{3}$
}

\begin{abstract}
ABSTRAK
Perkembangan dunia IT saat ini sungguh pesat. Tidak mengherankan memang bagi masyarakat yang khususnya tinggal di perkotaan. Dan tidak bisa dipungkiri lagi kecanggihan alat atau device yang kita gunakan selama ini sangat canggih dan dibutuhkan bagi semua kalangan masyarakat, tidak terkecuali para peternak ayam. Dalam permasalahan ini banyak ditemukan para peternak ayam masih menggunakan sistem manual mulai dari pemberian konsumsi pakan maupun temperatur suhu yang kadang berubahberubah setiap waktu. Maka dari itu diperlukan adanya sistem pengontrolan untuk pembudidayaan ayam tanpa mengganggu atau merusak sistem yang telah ada. Dengan adanya sistem pengendali menggunakan Smartphone memudahkan untuk pemberian konsumsi pada ayam. Dengan menggunakan Bluetooth semua bisa dikontrol diantaranya pemberian konsumsi dan menyalakan atau mematikan lampu. Alat yang digunakan untuk pemberian konsumsi antara lain Solenoid dan Pompa air akuarium. Kemudian menginstal aplikasi MIT App Inventor yang berjalan di sistem Android sebagai interfacenya. Lalu adanya sensor suhu LM-35 yang bisa membaca temperature suhu pada kandang dan menampilkan hasilnya pada LCD Display. Dan komponen utama ialah Arduino Uno, karena semua komponen tidak akan bisa berjalan tanpa instruksi dari Arduino Uno yang telah diprogram sedemikian rupa untuk bisa menjalankan semua instruksi komponen.
\end{abstract}

Kata Kunci : Arduino Uno, Bluetooth, Sensor suhu, Smartphone

\section{ABSTRACT}

The development of IT this time is really rapidly. No surprising for the people who live in urban areas particularly. And no denying the power of tool or device that we use during this very sophisticated and it takes to all the community, not excluding the chicken farmers. In these problems commonly found the chicken farmers are still using manual systems ranging from the provision of feed consumption and temperature temperatures sometimes changed every time. So it is necessary to control systems for the cultivation of chicken without disturbing or damaging the existing system. With the control system using smartphone makes it easy to provision in the consumption of chicken. By using Bluetooth all can be controlled such as granting consumption and turn on or turn off the lights. The tools that used for administration and consumption are Solenoid and aquarium water pump. Then install the MIT App Inventor applications that run on the Android system as the interface. Then the LM-35 temperature sensor that can read the temperature on the enclosure temperature and displays the results on the LCD Display. And the main component is an Arduino Uno, because all of the components will not be able to run without instructions from the Arduino Uno that have been programmed in such a way to be able to run all of the instruction component.

Keywords : Arduino Uno, Bluetooth, Temperature Sensor, Smartphone

Vol.3 No.1 - Februari 2017 


\section{PENDAHULUAN}

Perkembangan di dunia IT saat ini sungguh pesat. Tidak mengherankan memang bagi masyarakat yang khususnya tinggal di perkotaan. Dan tidak bisa dipungkiri lagi kecanggihan alat atau device yang kita gunakan selama ini sangat canggih. Contohnya handphone atau Telepon genggam yang sering kita gunakan setiap hari, sekarang tidak hanya untuk alat komunikasi, tetapi banyak fitur yang lebih kompleks. Seperti internet, Bluetooth, kamera, dan masih banyak lainnya. Jika salah satu fitur tersebut dapat difungsikan dengan benar dan baik maka bisa juga bermanfaat bagi orang lain.

Penggunaan Bluetooth yang terbatas bagi sebagian orang yang fungsinya hanya untuk mengirim dan menerima data atau file saja. Tapi bagi mahasiswa yang mendalami bidang ilmu komputer, khususnya Sistem Komputer penggunaan Bluetooth sangat banyak fungsinya. Salah satunya sebagai alat pengontrolan, tentunya dengan menginstal aplikasi yang sudah dimodifikasi agar bisa mengontrol alat-alat yang kerjanya membutuhkan daya listrik atau elektrik.

Dengan demikian penulis mencoba mengembangkan penggunaan bluetooth sebagai alat yang bermanfaat bagi masyarakat luas. Penulis mencoba membangun suatu kandang ayam yang bisa dikontrol dengan handphone secara nirkabel dengan memanfaatkan fitur bluetooth. Selama ini masih banyak pembudidayaan ayam dengan cara yang masih manual. Seperti, pemberian makan atau minum, menyalakan atau mematikan lampu, dan pemantauan suhu dikandang. Karena kondisi suhu kandang harus selalu dipantau.

Dari permasalahan tersebut dibuatlah suatu kandang ayam untuk memenuhi semua kebutuhan yang dijelaskan sebelumnya. Sehingga tidak perlu lagi memberi makan dan minum secara manual ke kandang, karena kandang ayam ini sudah dirancang untuk kebutuhan tersebut. Cukup dengan penggunaan Bluetooth dan dukungan aplikasi pada Smartphone untuk bisa mengontrol pemberian makan atau minum kapanpun. Dan untuk temperatur suhunya sendiri menggunakan sensor suhu LM-35 dengan LCD Display sebagai nilai keluarannya, terakhir adalah lampu yang bisa dikontrol dan dipasang didalam kandang untuk menjaga suhu dari ayam tetap stabil dan merasa nyaman didalam kandang.

\section{PERMASALAHAN}

Saat ini sistem pengontrolan untuk pembudidayaan ayam tidak memiliki fasilitas yang memadai dalam hal pemberian makan, minum, serta menghidupkan dan mematikan lampu guna mengatur temperatur suhu kandang masih secara manual sehingga diperlukan sistem yang dapat mengontrol pemberian makan dan minum serta memberikan informasi temperatur suhu kandang secara realtime dan sesuai dengan kebutuhan pakan ternak tersebut. 


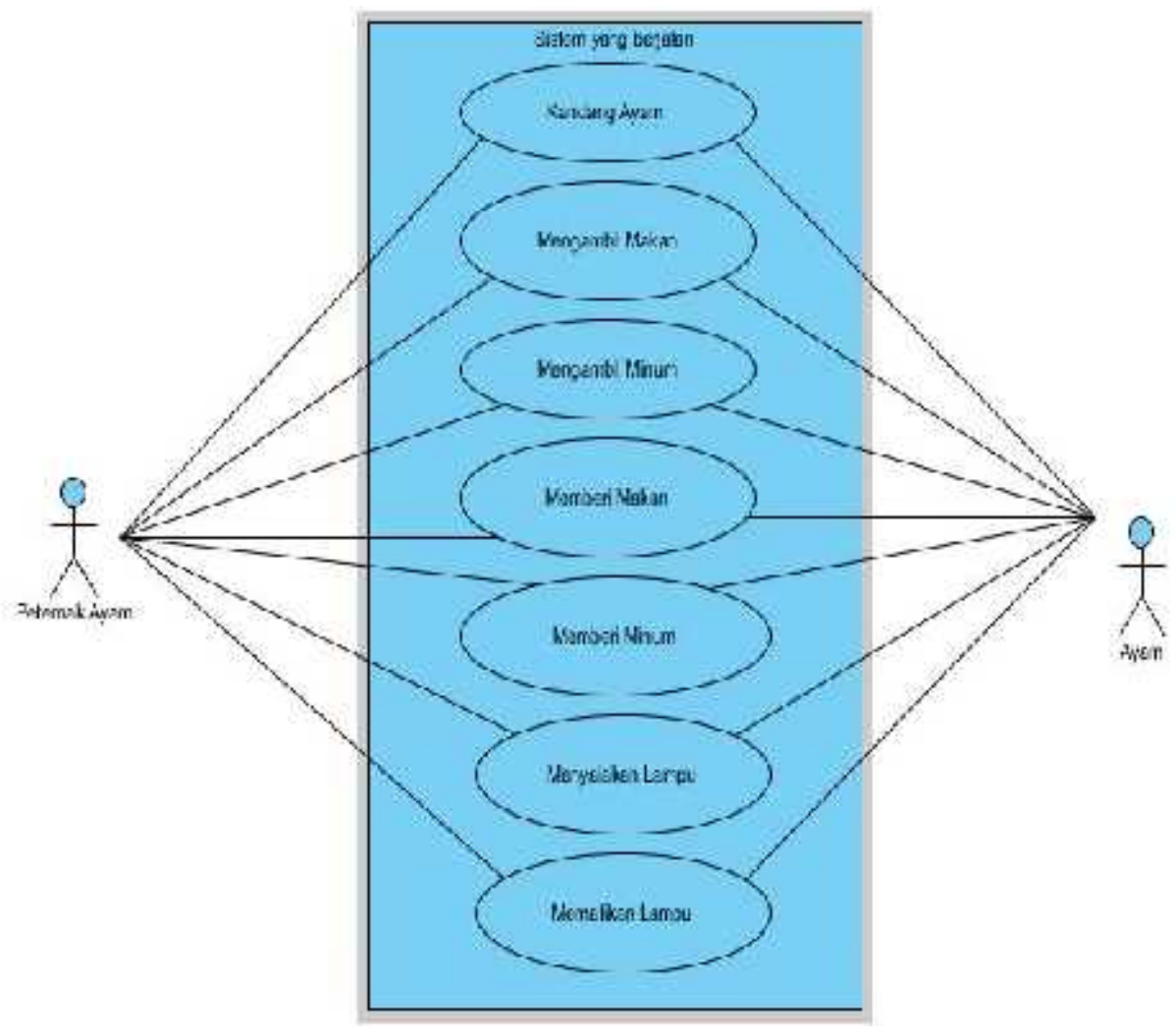

Gambar 1. Sistem yang Berjalan

Merancang sistem yang tepat guna dalam sistem pengontrolan kandang merupakan solusi yang tepat dari permasalahan yang ada, dengan membangun sistem yang lebih mumpuni dan efisien dalam pemberian pakan sehingga dapat lebih mudah dalam mengontrol tanpa harus mendatangi langsung ke kandang ternak. Dengan menggunakan aplikasi MIT App Inventor yang dapat dihubungkan melalui Bluetooth sebagai penunjang akan sangat membantu dalam pengontrolan. Berikut diagram sistem yang telah diusulkan. 


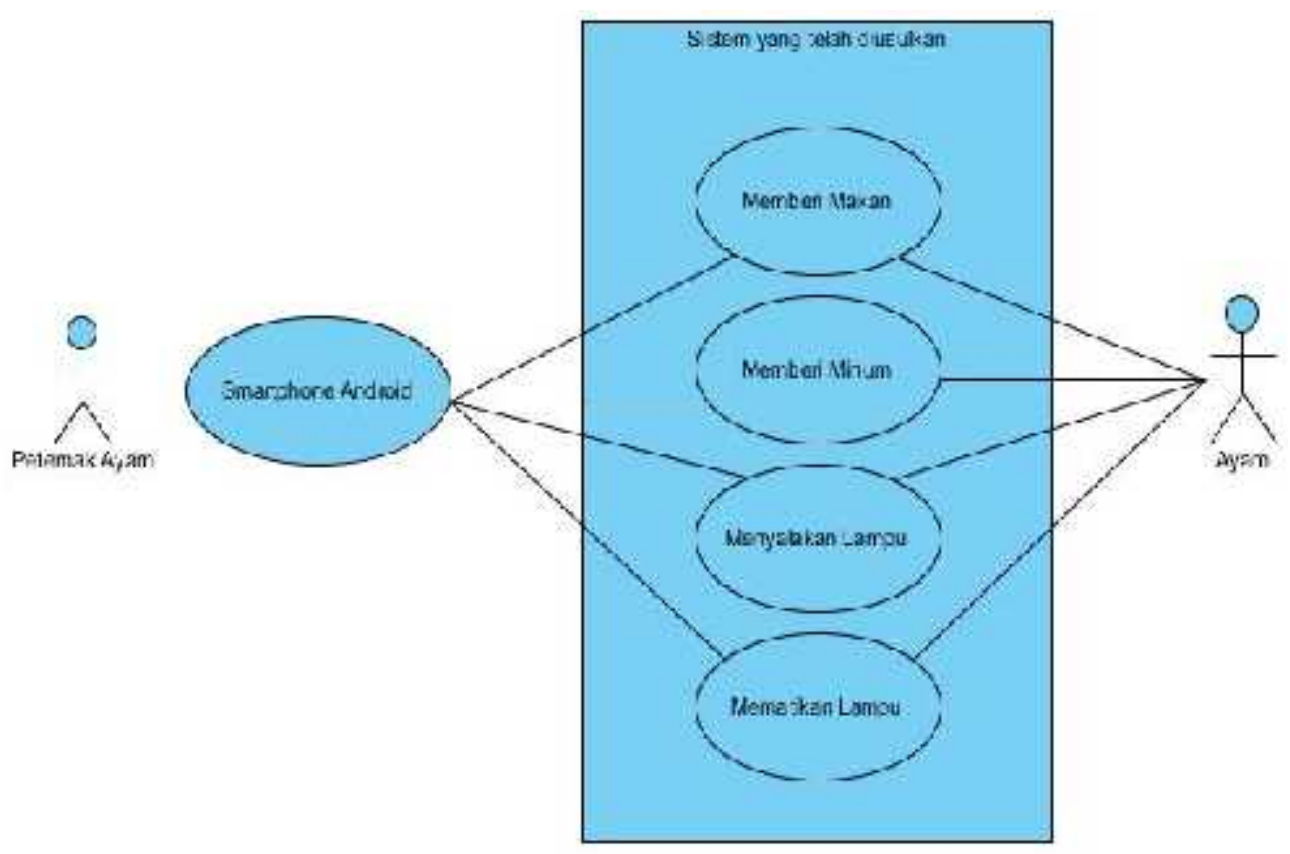

Gambar 2. Sistem yang telah diusulkan

\section{LITERATURE REVIEW}

Dalam upaya mengembangkan dan membangun sistem pengontrolan via bluetooth dengan menggunakan smartphone android sebagai interface ini perlu dilakukan literature review (study pustaka), sebagai salah satu dari penerapan metode penelitian yang akan dilakukan. Terdapat banyak penelitian lain yang menunjang penulis untuk melakukan penelitian, diantaranya:

1. Penelitian yang dilakukan oleh Egi Wahyu Ruchiyat dari STMIK Raharja yang berjudul "Alat Penyiram Tanaman Dan Memberi Pupuk Otomatis Menggunakan Sensor Suhu Berbasis Arduino Uno Pada Dinas Pertanian Dan Peternakan Kabupaten Tangerang" pada tahun 2015. Penelitian ini membahas tentang pengendalian terhadap tanaman dengan sistem otomatisasi menggunakan sensor suhu untuk membaca lingkungan sekitar. ${ }^{[1]}$

2. Penelitian yang dilakukan Dani Permana Koswara dari STMIK Raharja yang berjudul "Perancangan System Pemberi Pakan Hewan Otomatis Menggunakan Arduino Uno Berbasis Android Pada Petshop Vet De Villa" pada tahun 2015. Penelitian ini membahas tentang pemberian makan pada hewan peliharaan seperti kucing, dengan menggunakan motor servo sebagai buka tutup katup makanan, dan Bluetooth berfungsi untuk penghubung antara Smartphone Android dengan Bluetooth HC-06 yang sudah tersambung dengan mikrokontroler. ${ }^{[2]}$

3. Penelitian yang dilakukan oleh Enda dari STMIK Raharja yang berjudul "Perancangan Alat Untuk Menyalakan Dan Mematikan Motor Industri Menggunakan Smartphone Android Via Bluetooth" pada tahun 2015. Penelitian tersebut menggunakan Bluetooth sebagai sarana komunikasinya dan Smartphone sebagai pengontrolnya. ${ }^{[3]}$ 
4. Penelitian yang dilakukan oleh Yosafine Rifki dari STMIK Raharja yang berjudul "Rancang Bangun Pemberi Makan Dan Pemantau Akuarium Menggunakan Raspberry Pi Pada Pt. Dian Surya Global" pada tahun 2015. Penelitian ini membahas tentang pengontrolan untuk memberi makan ikan dan fungsi kamera sebagai pemantau terhadap ikan-ikan yang ada di dalam akuarium. ${ }^{[12]}$

5. Penelitian yang dilakukan oleh Rio Krismas Sebayang dari Universitas Lampung Yang berjudul "Perancangan Sistem Pengaturan Suhu Kandang Ayam Berbasis Mikrokontroler" pada tahun 2015. Penelitian ini membahas tentang pengaturan temperatur suhu didalam kandang ayam dengan menggunakan sensor suhu LM-35. ${ }^{[6]}$

6. Meri Kurniawati dan Chandra Esa Paramita dari Amik Gi Mdp Palembang Yang Berjudul "Alat Pengendali Makan Ikan Otomatis Di Akuarium Berbasis Mikrokontroler" pada tahun 2011. Penelitian ini tentang pemberian makan ikan secara otomatis dengan jadwal waktu yang telah ditentukan. ${ }^{[5]}$

Maka dari lima literature review diatas, sistem pemberian makan maupun temperatur sudah pernah dibahas pada penelitian sebelumnya. Dari beberapa literature review tersebut saya mengambil nomor 2 karena kesamaan dengan sistem pemberian makan, lalu penambahan pemberian minum dan menghidup matikan lampu melalui smartphone dengan menghubungkannya melalui media Bluetooth HC-06.

\section{PEMECAHAN MASALAH}

Dalam penulisan artikel ini digunakan beberapa metode penyelesaian masalah dengan tahapan sebagai berikut:

a. Planning:

- Menentukan aplikasi yang akan digunakan, contohnya MIT App Inventor.

- Memilih Hardware dalam pembangunan sistem.

b. Analisis:

- Membandingkan sistem yang sedang berjalan dengan sistem yang diusulkan.

c. Desain:

- Perancangan dilakukan dengan menggunakan bahasa pemrograman.

d. Implementasi:

- Implementasi dilakukan dengan cara memanfaatkan sistem yang dibangun untuk sistem pengontrolan pakan ternak.

\section{PERANCANGAN HARDWARE}

Perancangan hardware untuk merancang sistem pembudidayaan ternak ayam ini menggunakan komponen arduino uno sebagai modul untuk melakukan proses, modul Bluetooth HC-05 sebagai media komunikasi serial dengan smartphone, solenoid sebagai pembuka tutup makan ternak, pompa air yang berfungsi mengaliri air ke wadah untuk minum ternak. 
Smartphone android sebagai media interface untuk menampilkan daftar menu yang akan diproses dan rangkaian catu daya 5 Volt sebagai sumber tegangan bagi komponen-komponen tersebut.

Agar mempermudah dalam menjelaskan perancangan perangkat keras, maka di gambarkan alur dan cara kerja perangkat keras pada rangkaian keseluruhan.

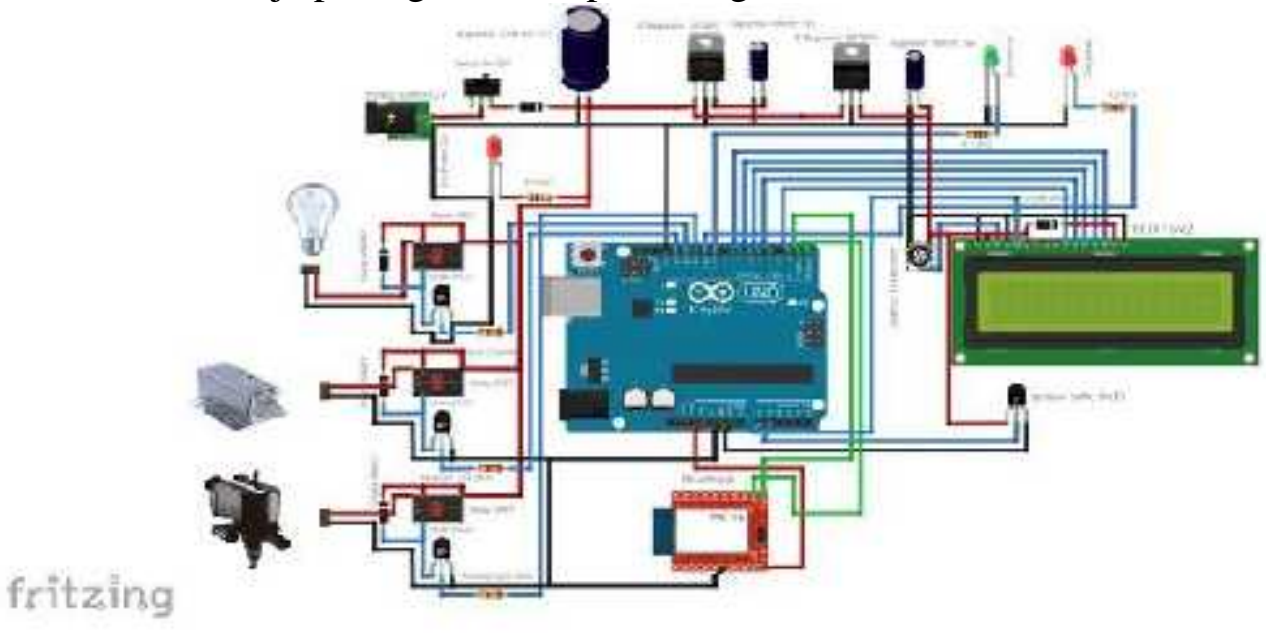

Gambar 3. Skematik Keseluruhan

Rangkaian keseluruhan dari sistem ini merupakan penggabungan dari beberapa rangkaian seperti arduino uno, modul Bluetooth HC-05 dengan komunikasi serial untuk komunikasi antara arduino uno dan smartphone, solenoid sebagai penggerak katup untuk membuka atau menutup makanan ternak, pompa air untuk mengaliri air minum ternak, serta lampu untuk menjaga temperatur suhu agar tetap stabil dan sebagai tambahan IC converter 5 volt ke 3 volt. Tegangan 3 volt digunakan modul Bluetooth HC-05.

\section{Arduino Uno}

Arduino uno adalah kit elektronik atau papan rangkaian elektronik open source yang di dalamnya terdapat komponen utama, yaitu sebuah chip mikrokontroller dengan jenis AVR dari perusahaan Atmel. Arduino uno memiliki 14 pin input dari output digital dimana 6 pin input tersebut dapat digunakan sebagai output PWM (Pulse Widht Modulation) dan 6 pin input analog, $16 \mathrm{MHz}$ osilator kristal, koneksi USB, jack power, ICSPheader, dan juga tombol reset.

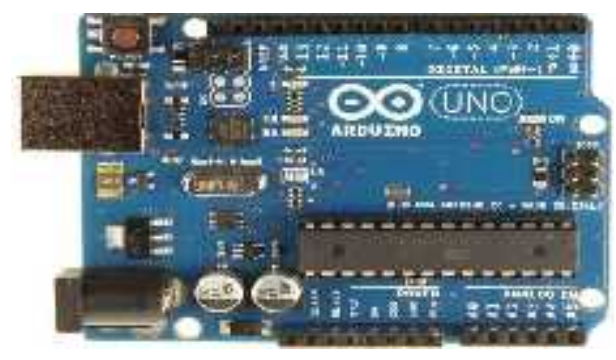

Gambar 4. Arduino Uno 


\section{Modul Bluetooth HC-05}

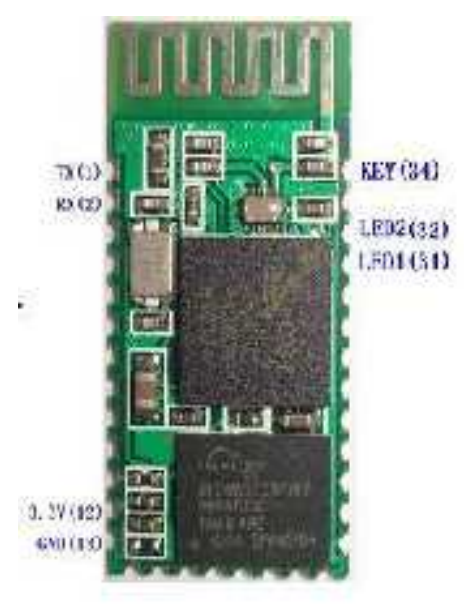

\section{Gambar 5. Bluetooth}

Dalam perancangan Bluetooth ini, menggunakan modul Bluetoot HC-05. Komponen ini berfungsi sebagai media komunikasi antara arduino uno dan smartphone, modul Bluetooth HC05 bekerja dengan sumber tegangan 3 Volt yang berasal dari IC Converter yang menurunkan tegangan dari 5 Volt menjadi 3 Volt. Modul Bluetooth HC-05 memiliki spesifikasi sebagai berikut:

- Bluetooth Protocol: Bluetooth Specification V2.0+EDR

- Frequency: 2,4 GHz ISM band

- Modulation: GFSK (Gaussian Frequency Shift Keying)

- Emission Power: $\leq 4 \mathrm{dBm}$, Class 2

- Sensitivity: $\leq-84 \mathrm{dBm}$ at $0.1 \%$ BER

- Speed: Asynchronous: 2.1 Mbps (Max) / $160 \mathrm{kbps,}$

- Synchronous: $1 \mathrm{Mbps} / 1 \mathrm{Mbps}$

- Security: Authentication and encryption

- Profiles: Bluetooth serial port

- Power Supply: +3.3VDC 50mA

- Working Temperature: $-20 \sim+75$ Centigrade

- Dimension: $26.9 \mathrm{~mm}$ x $13 \mathrm{~mm}$ x $2.2 \mathrm{~mm}$

\section{Solenoid}

Solenoid adalah alat yang dapat mengubah energi listrik menjadi energi mekanik atau linier. Solenoid yang paling umum biasanya menggunakan medan magnet yang dibuat dari arus listrik yang ditrigger sebagai aksi kerja dorong atau tarik pada sebuah objek sebagai strarter, valve, switch dan latches.

Jenis paling sederhana dari solenoida mengandalkan dua aspek utama untuk fungsi solenoid tersebut, yaitu sebuah kawat (atau berenamel) terisolasi yang dibentuk menjadi gulungan ketat, dan batang yang terbuat dari besi atau baja. Batang besi atau baja merupakan 
feromagnetik, sebuah properti yang dapat berfungsi sebagai elektromagnetik saat diberi arus listrik.

Ketika diberi arus listrik, kawat yang dibentuk menjadi koil menerima arus. Medan magnet yang dihasilkan menarik besi atau batang baja dengan kuat. Batang yang dihubungkan pada sebuah pegas bergerak ke kumparan dan akan tetap pada posisinya sampai arus dihentikan, kondisi pegas saat ini menjadi tertekan. Ketika arus dimatikan, pegas kembali ke posisi semula dan menarik batang besi atau baja pada posisi awalnya.

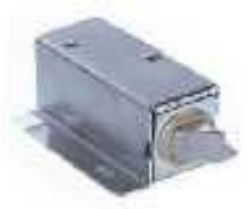

\section{Gambar 6. Solenoid}

\section{Pompa Air}

Sesuai namanya, pompa air listrik ini penggunaannya dicelupkan ke dalam air. Penggunaan yang umum adalah pompa air yang dipakai dalam aquarium untuk mengalirkan air ke tempat penyaringan air sehingga air aquarium terjaga kejernihannya untuk waktu yang lebih lama.

Cara kerjanyapun sama seperti pompa air listrik di atas, memanfaatkan daya centrifugal dari perputaran kipas impeller untuk mendorong air ke atas. Jenis pompa air celup ini cukup banyak tergantung keperluannya.

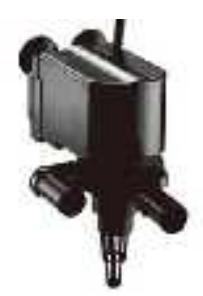

\section{Gambar 7. Pompa Air}

\section{Sensor Suhu LM-35}

Sensor suhu-LM 35 adalah sensor temperatur paling banyak digunakan umtuk praktik, selain harga yang murah, dalam linearitasnya lumayan bagus. LM-35 tidak membutuhkan kalibrasi eksternal yang menyediakan akurasi $\pm 1 / 4^{\circ} \mathrm{C}$ pada temperature ruangan dan $\pm 3 / 4^{\circ} \mathrm{C}$ pada kisaran $-55^{\circ} \mathrm{c}$ sampai dengan $+150^{\circ} \mathrm{c}$. LM35 dimaksudkan untuk beroperasi pada $-55^{\circ} \mathrm{c}$ hingga $+150^{\circ} \mathrm{c}$, sedangkan LM35C pada $-40^{\circ} \mathrm{c}$ hingga $+110^{\circ} \mathrm{c}$, dan LM35D pada kisaran $0-100^{\circ} \mathrm{C}$. 


\section{Gambar 8. Sensor Suhu LM-35}

\section{Rangkaian Catu Daya}

Catu daya sebagai power supply adalah sebuah piranti elektronika yang berguna sebagai sumber daya untuk piranti lain yang sangat penting. Dalam realisasi perangkat keras yang berupa solenoid dan pompa air. pada keseluruhan rangkaian sistem di sini membutuhkan catu daya. Gambar 8, merupakan gambar rangkaian catu daya yang terhubung dalam suatu rangkaian sistem. Uji coba dilakukan dengan menggunakan lampu LED (light-emitting diode), sebagai output dari tegangan kerja pada sebuah rangkaian catu daya, uji coba rangkaian catu daya dapat di lihat pada gambar 8 sebagai berikut:

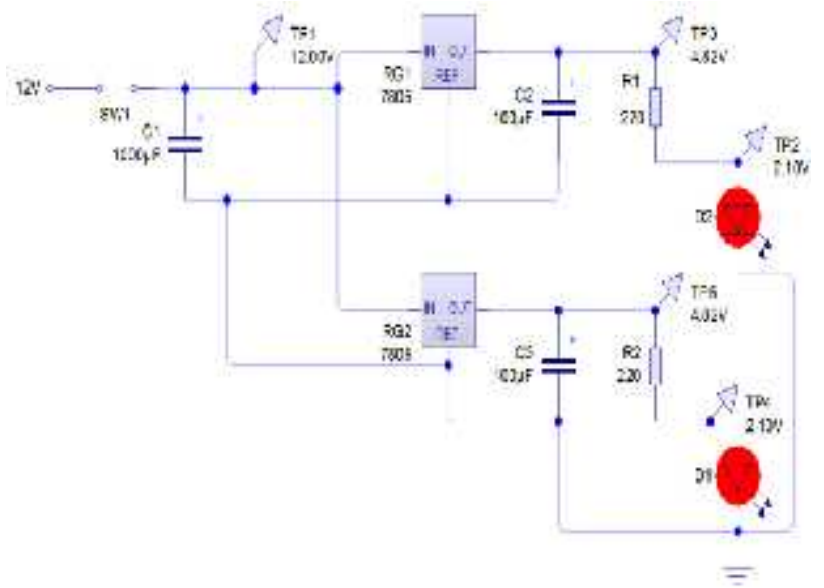

Gambar 9. Pengujian rangkaian catu daya

\section{IMPLEMENTASI}

Dalam pelaksanaan atau implementasi pembuatan sistem perancangan program dapat digambarkan dalam bentuk flowchart sehingga dapat mempermudah dalam melakukan dan merancang langkah-langkah atau proses dengan benar. Adapun bentuk dari flowchart keseluruhan dari sistem yang dibuat dapat dilihat pada gambar berikut. 


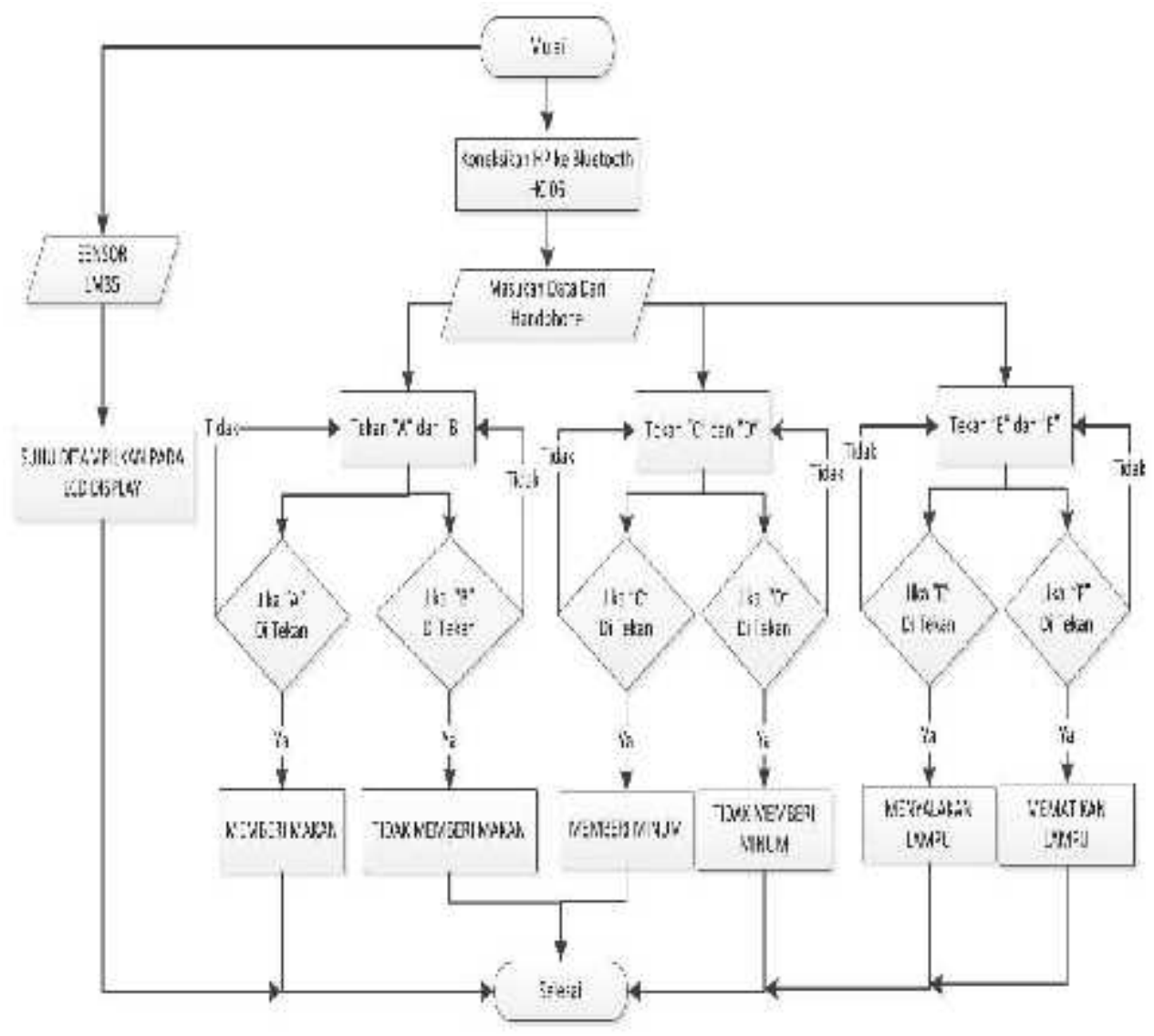

Gambar 10. Flowchart Sistem

Adapun bentuk nyata prototype kandang ayam dengan rancangan sistem yang telah diusulkan.

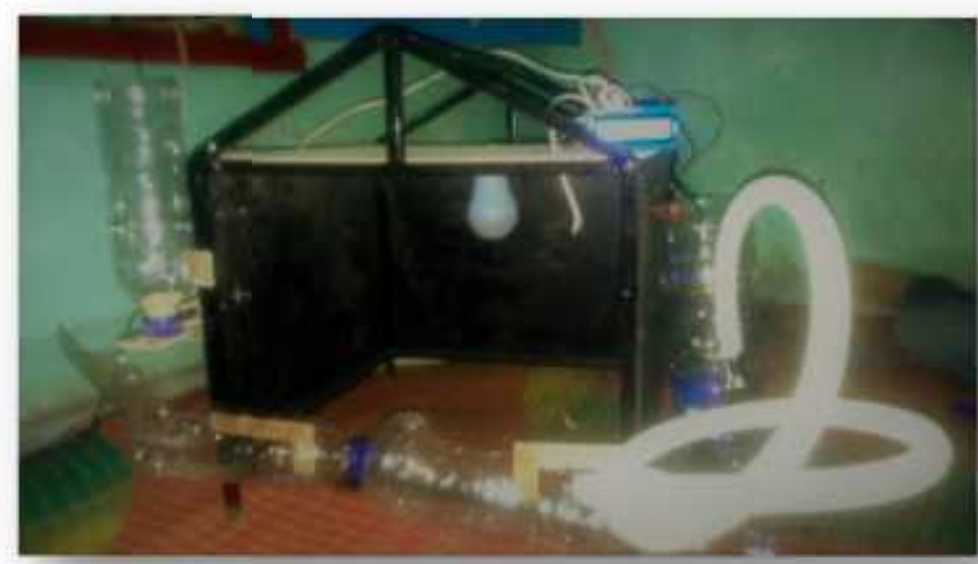

Gambar 11. Kandang Ayam

Vol.3 No.1 - Februari 2017 


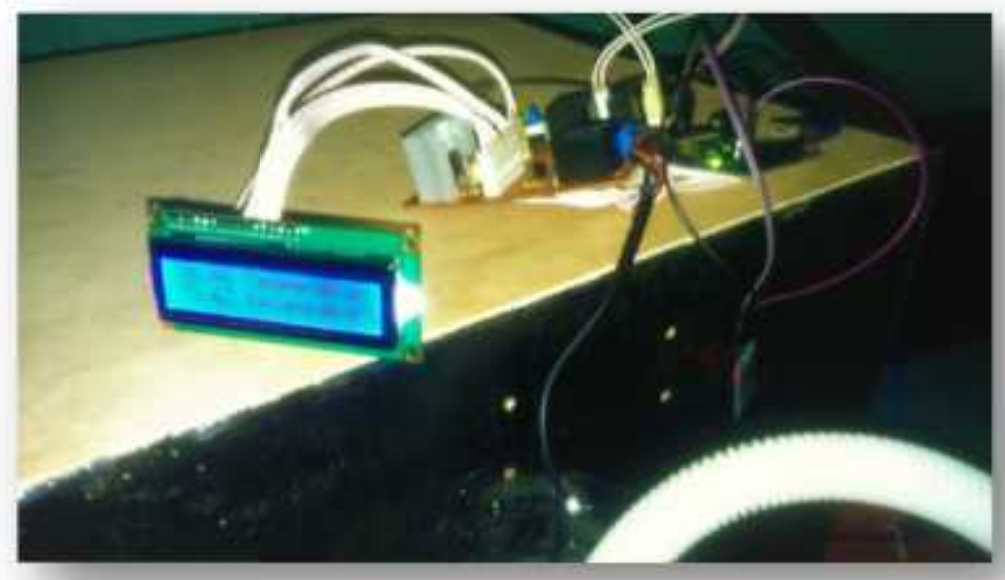

Gambar 12. Komponen Hardware dan Elektronika

Sehingga mutu yang didapat dari rancangan ini lebih praktis dan efisien, karena memudahkan peternak ayam dalam pemberian konsumsi pakan ayam yang dapat dikontrol dengan smartphone melalui fitur Bluetooth. Jadi tidak perlu terjun langsung kedalam kandang hanya untuk memberi makan dan minum ayam.

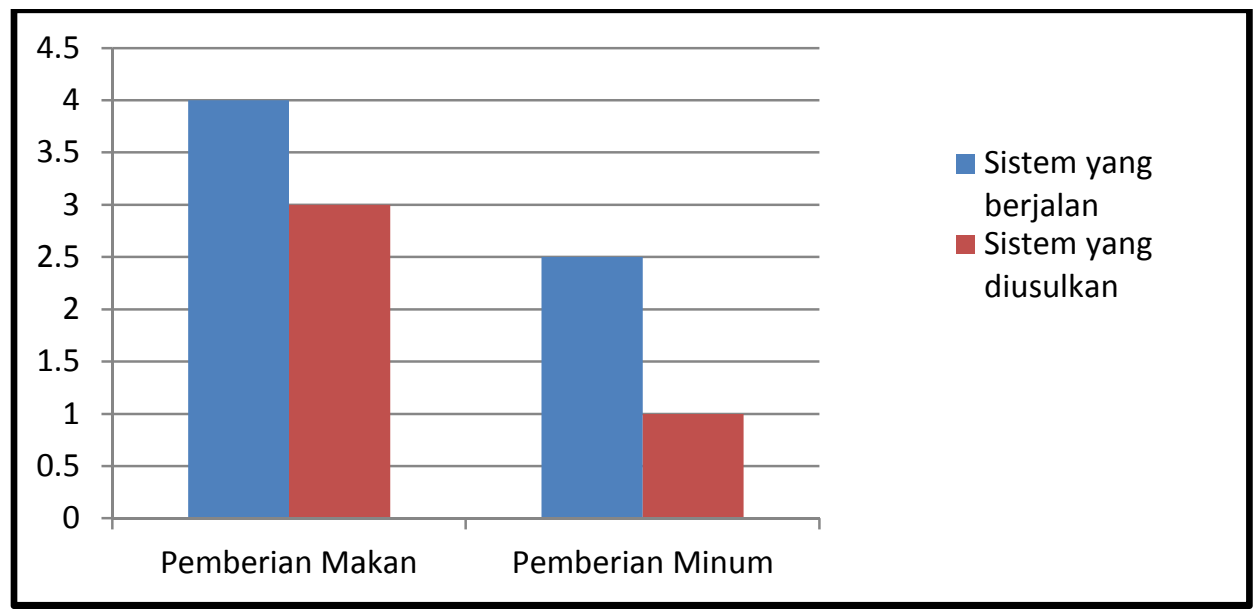

\section{Gambar 13. Grafik Waktu Pemberian Makan dan Minum Ayam}

Grafik diatas merupakan waktu (dalam menit) yang dibutuhkan untuk pemberian konsumsi pakan ayam. Maka, dapat ditarik kesimpulan bahwa dengan adanya rancangan pengontrolan ini, lebih kepada efisiensi waktu tanpa harus memberi pakan secara manual. Sehingga waktu yang dibutuhkan tidak lama. Dan dari grafik tersebut didapat dari hasil analisa. Semakin besar kandang semakin besar pula waktu dan tenaga yang dibutuhkan untuk memberi paka secara manual. Dengan sistem ini diharapkan untuk mempersingkat waktu peternak dalam hal pemberian pakan ayam. 


\section{Tampilan Program Aplikasi}

Pada MIT App Inventor memiliki 2 sisi, yaitu sisi Designer dan sisi Blocks. Pada sisi Designer berfungsi untuk mendesain tampilan aplikasi. Sedangkan untuk sisi Blocks adalah tempat dimana setiap aktivitas dan interaksi pengguna diproses, mengatur apa yang akan terjadi jika interaksi tertentu dilakukan melalui layar smartphone.

Berikut adalah gambar sisi design dan sisi blocks yang telah dirancang sebagai gambaran untuk diterapkan didalam Smartphone Android.

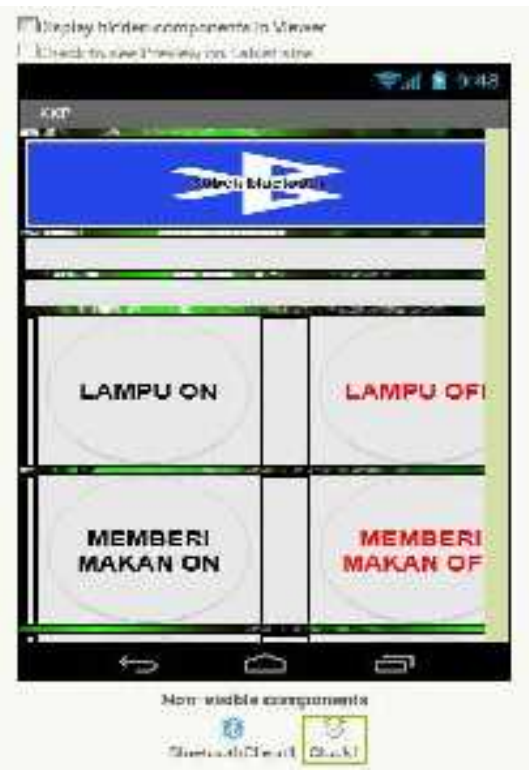

\section{Gambar 14. Sisi Designer Aplikasi}

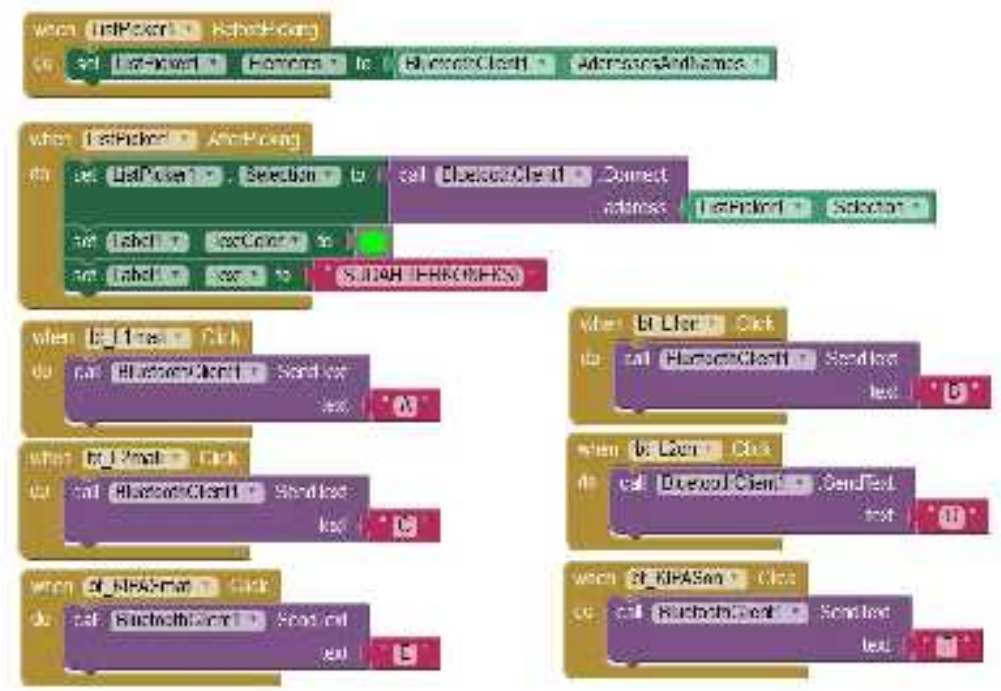

Gambar 15. Sisi Blocks Aplikasi 


\section{Listing Program}

Perancangan perangkat lunak adalah melakukan penulisan listing program ke dalam software Arduino IDE versi 1.6.6 dengan menggunakan bahasa C, dimana perintah- perintah program tersebut akan di eksekusi oleh hardware atau sistem yang dibuat. Berikut listing program yang telah dibangun:

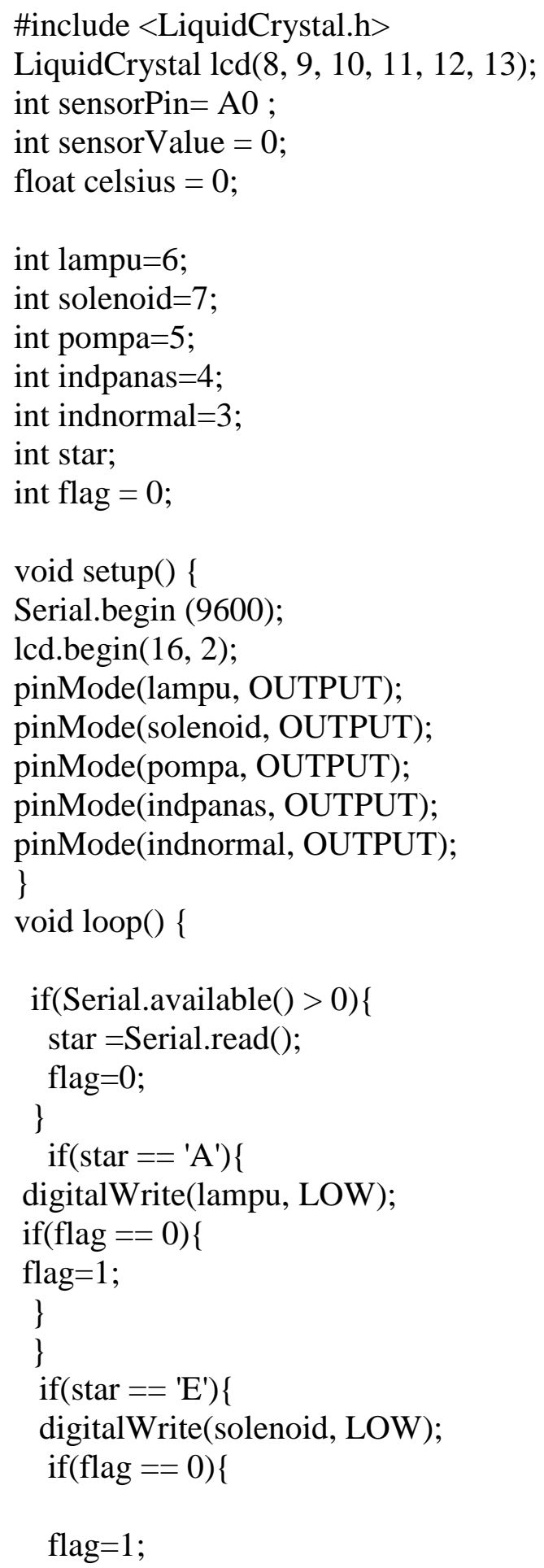




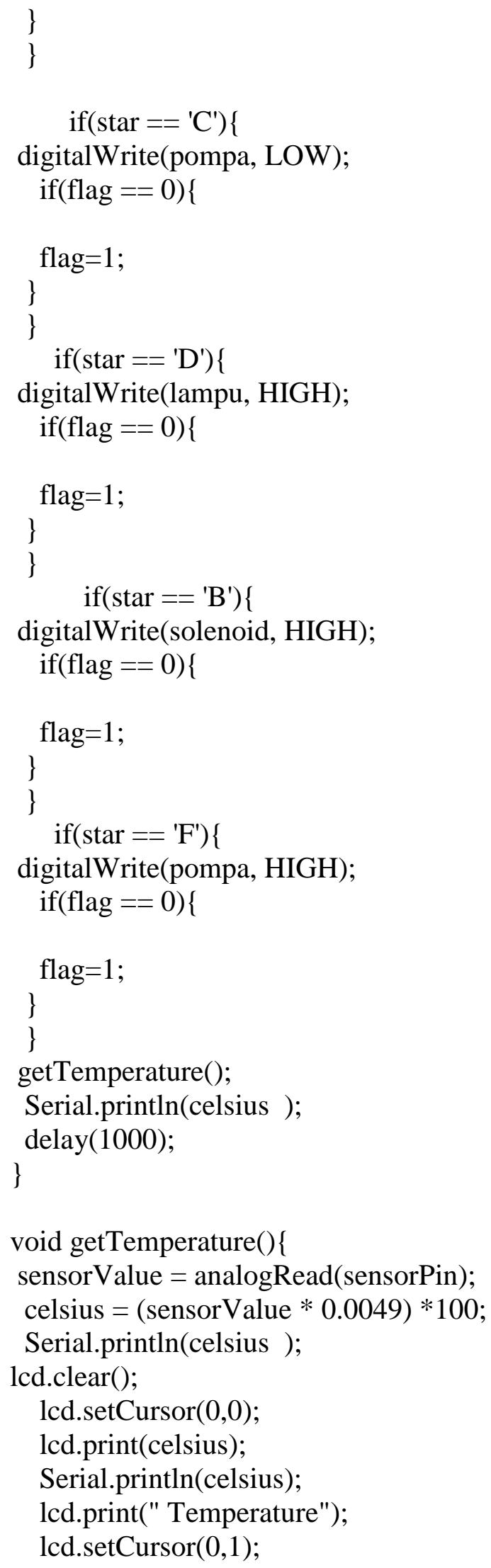




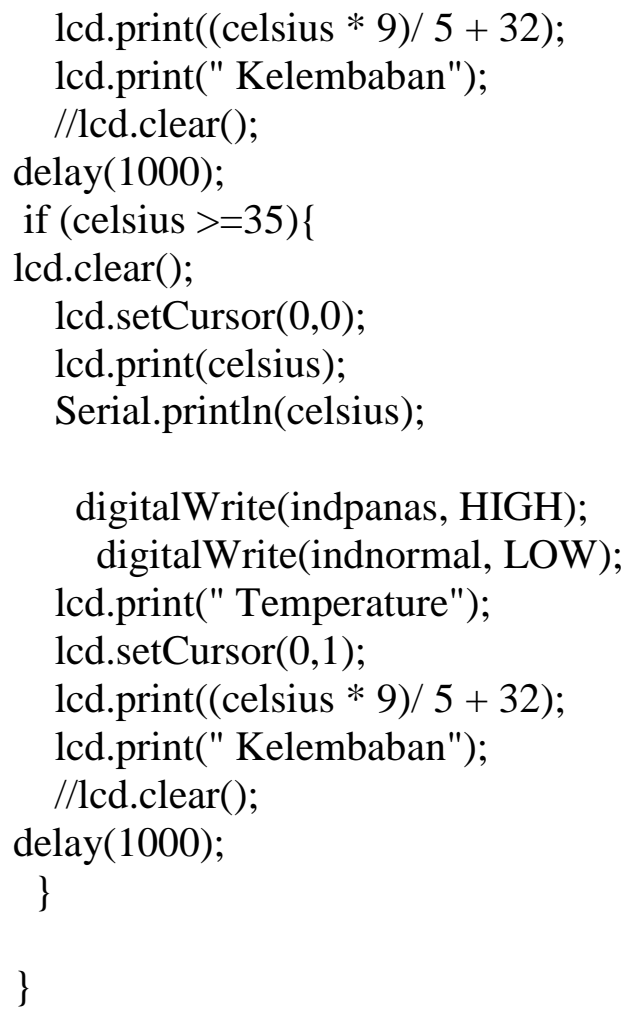

\section{KESIMPULAN}

Dari perancangan yang dilakukan dapat diperoleh kesimpulan sebagai berikut:

1. Pengontrolan dengan menggunakan Smartphone akan lebih memudahkan pengguna untuk memberikan pakan dan minum secara otomatis serta fungsi lampu untuk menjaga temperatur suhu didalam kandang.

2. Pengontrolan ini menggunakan sebuah aplikasi yang sudah dirancang sedemikian rupa agar pengguna dapat dengan mudah menggunakannya.

3. Pengontrolan ini menggunakan media Bluetooth sebagai koneksinya yang terhubung langsung antara Smartphone dengan komponen-komponen yang ada pada kandang.

\section{DAFTAR PUSTAKA}

[1] Egi Wahyu Ruchiyat. Alat Penyiram Tanaman dan Memberi Pupuk Otomatis Menggunakan Sensor Suhu Berbasis Arduino Pada Dinas Pertanian Dan Perternakan Kabupaten Tangerang. Tangerang: STMIK Raharja, 2015.

[2] Dani Permana Koswara. Perancangan System Pemberi Pakan Hewan Otomatis Menggunakan Arduino Uno Berbasis Android Pada Petshop Vet De Villa. Tangerang: STMIK Raharja, 2015.

[3] Enda. Perancangan Alat Untuk Menyalakan dan Mematikan Motor Industri Menggunakan Smartphone Android via Bluetooth. Tangerang: STMIK Raharja, 2015.

[4] Komputer, Wahana. Membuat Aplikasi Android Untuk Tablet dan Handphone. Jakarta: PT Elex Media Komputindo, 2012. 
[5] Meri Kurniawati, Chandra Esa. Alat Pengendali Makan Ikan Otomatis Di Akuarium Berbasis Mikrokontroler. Palembang: AMIK GI MDP Palembang, 2011

[6] Rio Krismas Sebayang. Perancangan Sistem Pengaturan Suhu Kandang Ayam Berbasis Mikrokontroler. Lampung: Universitas Lampung, 2015.

[7] Rusmadi, Dedy. Mengenal Komponen Elektronika. Bandung: Pionir Jaya, 2014.

[8] Saefullah, Asep, Dewi Immaniar dan Reza Amar Juliansyah. Sistem Kontrol Robot Pemindah Barang Menggunakan Aplikasi Android Berbasis Arduino Uno. CCIT Journal Vol. 8, No. 2, Januari 2015.

[9] Safaat, Nazruddin. Android Pemrograman Aplikasi Mobile Smartphone dan Tablet PC Berbasis Android. Jakarta: Informatika, 2011.

[10] Sudaryono, Muhamad Gunawan, Hilmi Nugraha. Sistem Pesan Makanan Via Bluetooth Dengan Interface Android Berbasis Arduino Uno. ICIT Journal Vol.2 No.1, Februari 2016.

[11] Syahrul. Pemrogramman Mikrokontroller AVR Bahasa Assembly Dan C. Bandung: Penerbit Informatika Bandung, 2014.

[12] Yosafine Rifki. Rancang Bangun Pemberi Makan dan Pemantau Akuarium Menggunakan Raspberry Pi Pada PT. Dian Surya Global. Tangerang: STMIK Raharja, 2015. 